\title{
Crystallographic Principal Modulation and Metal Core - Crystal Structure Exchangeable: Computational And Molecular Docking Simulation
}

Doaa S. El Sayed ( $\sim$ doaasaied75@yahoo.com )

Alexandria university Faculty of Science https://orcid.org/0000-0002-2366-418X

\section{Research Article}

Keywords: crystallographic modulation, computational analysis, DFT method, Hirschfeld surface, molecular docking

Posted Date: October 25th, 2021

DOl: https://doi.org/10.21203/rs.3.rs-996292/v1

License: (c) (1) This work is licensed under a Creative Commons Attribution 4.0 International License.

Read Full License 


\section{Abstract}

Keeping in mind, the structural analysis can be modified and regulated with computational background then advances in complex structural analysis thereof. Crystallographic data of metal complexes can be modulated to form a huge number of other metal complexes that can be synthesized and applied in recent further fields. The crystal structure of Pd complex was studied as previously reported and identified to be exchanged with other metals such Zn and Ni. DFT methodology was applied to investigate the difference in electronic properties of these complexes-exchangeable metals. Spectroscopic studies were performed to compare the difference in results. Hirschfeld surface analysis deeply illustrated the intermolecular contacts of the reported Pd crystal structure. Molecular docking simulation was applied on the previously synthesized complex and the investigated ones using E-coli protein target with comparison in details.

\section{Introduction}

Transition metals, that represent the core of coordination chemistry, are used in several purposes such catalytic and biological antitumor fields. These applications stimulate the researchers to think in more advance of modulation larger molecular systems perform the same behavior like analogues [1]. Several studies on platinum complexes succeeded in exploring them as a proved drugs as antitumor agents [2, 3]. Palladium is a soft lewis acid like platinum and have similar biological and thermodynamic properties, due to this reason, palladium-based compounds were synthesized and gave a large area for studying their biological behavior $[4,5]$.

Several interesting works in the literature were recently reported measuring different intensities in palladium-based complexes activity on species variations like fungi and bacteria [6-10]. It was recently demonstrated that palladium (II) complexes including a thiazoline derivative ligand helped in reduction of proliferation capacity also induced apoptosis in the cell lines of colon HT-29 and lymphoma U-937 [11]. Coordinated ligand modifications in metal center also enhance the cytotoxic activity of metal complexes [12-14].

Examining the geometrical structure of most Pd-complexes, it was found that 4-bonded coordinated structure locate between tetrahedral and square planar geometrical pathway depending on the electronic configuration of the metal. Also, a mutual arrangement around the planar environment basically depends the interacting molecular orbitals resulting the implementation of optimal planar geometry of the compound causing ligand-ligand charge transfer reactions [15-17]

To view of mentioned above, researches move towards the molecular design study of many metal complexes preferring the square-planar structure.

The widespread availability on compound transformation and atoms rearrangement with different computational approaches open the door to exploring and investigating different models may be carry 
significant properties help in several aspects. Drug design can export the same meaning of metalcoordination modulated compounds.

Density functional theory (DFT) methods are a strong and powerful computational technique in molecular modeling and drug design. Beside metals, ligands act as heterocyclic chelated systems help strongly in investigating the bioactive systems in pharmaceutical and medicinal applications.

The aim of this current study motivates investigation of metal-core complexes with distinguishable properties which lead to preference of metal complexes crystal structure synthesis but no other formed. Crystallographic modification structure gives new results about the formation of the crystal structure. Pdheterocyclic framework was selected as a synthesized crystal structure to implement and design a structure model with different metals such $\mathrm{Zn}$ and Ni. These types of metals were selected according to their ultra-ability in forming complexes with different heterocyclic ligands with different geometries.

\section{Methodology}

\subsection{Experimental background}

X-ray data of Pd-morpholine derivative complex was translated in a CIF file which was significantly downloaded from the Crystallography Open Database (COD), http://www.crystallography.net. These data are publicly available for researchers in order to make investigation and modifications leading to further study. Pd-complex CIF file was read in mercury software to detect the short contacts in the crystal unit especially intra and intermolecular $\mathrm{H}$-bond formation. From the data gathered, it was found that palladium has a square planar geometrical structure with bidentate chelating ligand and two coordinated $\mathrm{Cl}$ atoms [18].

According to the mode of binding, the metal-complexes in Fig. 1 occur in the cis isomer and face difficulties in trans-isomer synthesis. The chelating morphine derivative ligand bind with the mode to be difficult undergoes rotation. Also, the aliphatic and aromatic ring strains hinder the structure transformation. Exchanging of $\mathrm{Pd}$ from second raw of periodic table with $\mathrm{Ni}$ in the first raw but at the same group with similar general electronic configuration can explore other synthesized $\mathrm{Ni}$-complexes have the same electronic behavior like Pd-complexes. Also, exchanging of Pd-complexes with other first raw periodic table metal such $\mathrm{Zn}$ in other group give the chance to investigate its comparable crystallographic behavior.

\subsection{Computational advances}

Powerful supported computational programs were used in this study. Guassian 09 software [19] was applied on the X-ray structure of Pd complex and its modified crystallographic data included using B3LYP/LanL2DZ method that involve a wide range of molecular systems calculations especially metal core complexes [20]. Guass view [21] and mercury 4.0 software [22] were used for output structure 
visualization, atom labelling and color editing. Molecular docking simulation was applied using iGemdock software [23] under the default setting. E-coli expression system was selected for this analysis, where the types of organisms responsible for bacterial infection are Listeria monocytogenes protein target of PDB 106S and Brucella suis protein target of PDB 2BHM were downloaded from the protein data bank (https://www.rcsb.org/) as a PDB file. There was a preparation step in which water, ions and any extra useful species should be removed from the receptor. The investigated guest complexes were used in their optimized structure. Hirschfeld and different fingerprint plots were studied using crystal explorer 21.5 program [24]. The results originated from the crystallographic file of Pd-morpholine derivative complex.

\section{Results And Discussion}

\subsection{Experimental work investigation}

As shown in Fig. 2 the huge number of short contacts in the Pd-complex crystal structure gives evidence about the perfect arrangement of molecules in the unit cell and that leading to think about formation of other metal complexes of parallel arrangement including the same chelating ligand species. Atom speciation short contacts occupy an important space including intramolecular $\mathrm{C} . \mathrm{H}$, intermolecular $\mathrm{O} . . \mathrm{H}$ and intramolecular besides intermolecular $\mathrm{Cl} . . \mathrm{H}$ contacts, but the investigated results not show N..H and S..H either intra or intermolecular contact type. This is attributed to the chelating bidentate ligand (coordinate with $\mathrm{N}$ and $\mathrm{S}$ ) face most of its electronic density around the core of Pd metal.

\subsection{DFT crystallographic modulation}

To compare between the modulated metal structures with the experimental data, Table 1 presents some important geometrical bond lengths and bond angles of the studied complexes. The observed X-ray geometrical indices were compared with the calculated results using DFT/B3LYP/LanL2DZ effective method in gas phase. The experimental Pd1-S2, pd1-Cl3, Pd1-Cl4 and Pd1-N5 bond lengths have values $2.260,2.328,2.293$ and $2.102 \AA$, respectively. There is a satisfied computational result with the experimental ones except in case of Zn-morpholine complex in which Zn1-S2 bond length is $2.692 \AA$. This difference may be attributed to the weak bond formed between $\mathrm{Zn}$ atom and $\mathrm{S}$ atom of the ligand destroying the molecular stability of the unit cell structure. X-ray bond angles of S2-M1-Cl3, S2-M1-Cl4, S2-M1-N5, Cl3-M1-Cl4, Cl3-M1-N5 and Cl4-M1-N5 are 169.0, 88.1, 89.1, 91.0, 92.7 and 174.3, respectively. evaluating the bond angles of the studied complexes, it was found the computational results of $\mathrm{Pd}$ complex move in the same trend leading to formation of a square planar structure, also, in case of $\mathrm{Ni}-$ complex the data calculated are relatively closer to P-complex indicating a square planar Ni-complex formation. On the contrary, the data investigated for $\mathrm{Zn}$-complex not as the same in both $\mathrm{Pd}$ - and $\mathrm{Ni}$ structures. Bond angles values in $\mathrm{Zn}$-complex insight a tetrahedral structure formation. Fig. 3 illustrates theoptimized structures of the studied complexes with full labeled atoms. 
Table 1

Geometrical parameters of X-ray Pd complex and the modulated structures (Pd, $\mathrm{Zn}$ and $\mathrm{Ni}$ ) using DFT/LanL2DZ method

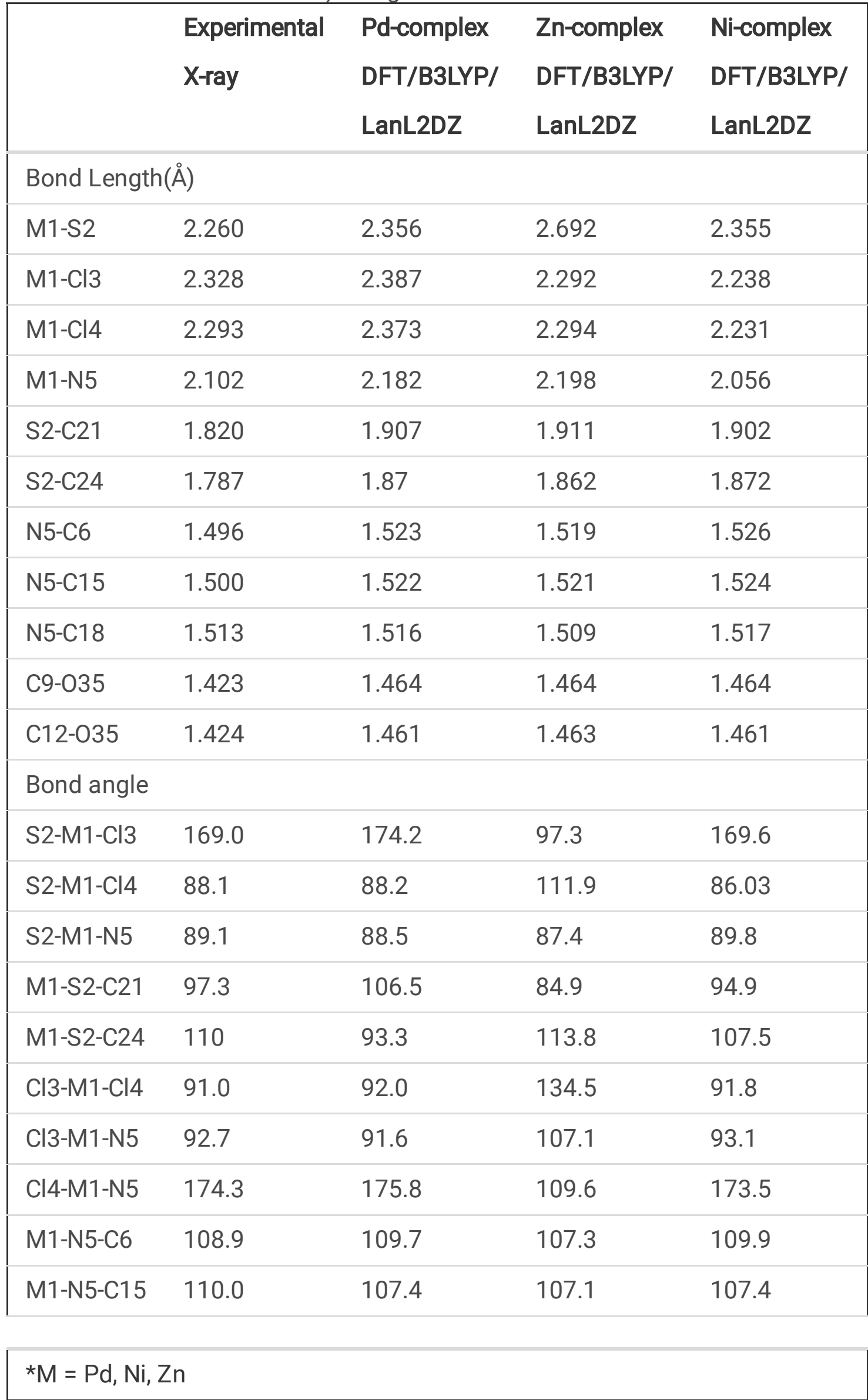




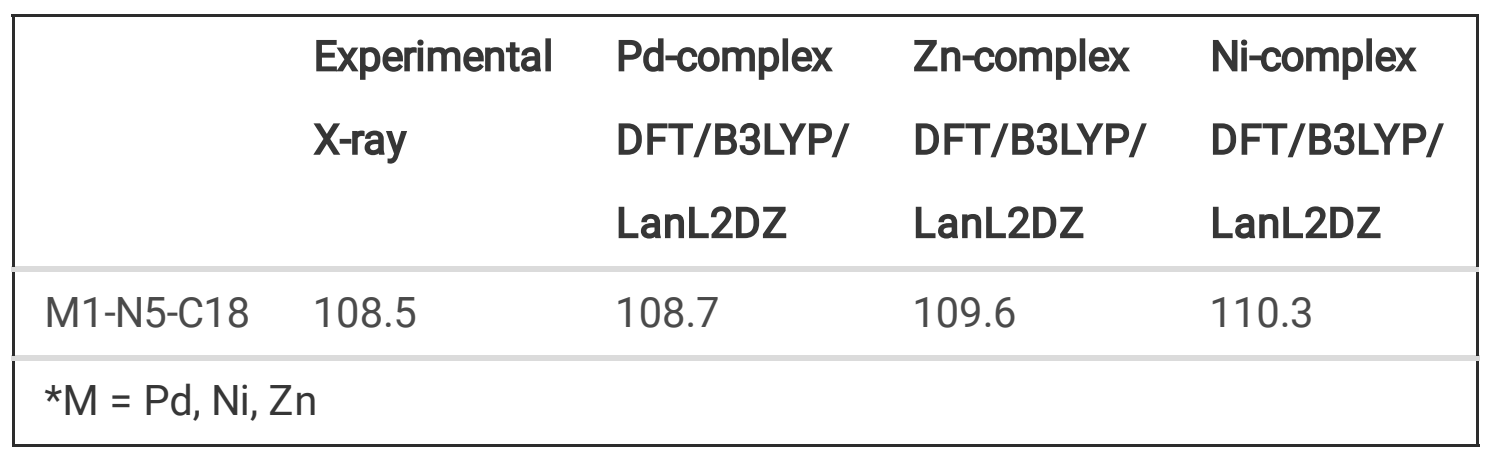

To examine the natural bond orbital analysis, the atomic charges of the compound must be in the full optimized state till reach the ground state stationary point.

Table 2 present the atomic charges calculated with NBO method for the studied complexes optimized in gas state. Imaginarily about the electronic behavior around the central metal atom increase according to the affinity of the metal to electrons. The atomic partial charge around $\mathrm{Pd}$ is 0.187 and around $\mathrm{Ni}$ atom is 0.242 , these values are positive small compared with $\mathrm{Zn}$ atom (1.043). This difference in charges indicate the atomic orbitals of $\mathrm{Pd}$ and $\mathrm{Ni}$ become strongly combined with the atomic orbitals of coordinated ligands that can lead to a markedly increasing in metal-ligand charge transfer but the atomic orbitals combination is considered as a weak metal-ligand charge transfer reaction. Also, the strong combination in atomic orbitals of $\mathrm{Pd}$ and $\mathrm{Ni}$ can be proved by the high positive charge value on $\mathrm{S} 2$ atom ( 0.381 and $0.369)$ compared with the value $(0.198)$ in $\mathrm{Zn}$-complex. The charges on $\mathrm{Cl}$ atoms are small with negative values in both $\mathrm{Pd}$ and $\mathrm{Ni}$ complexes, on the contrary, charges on $\mathrm{Cl}$ atoms are higher with negative values. As the same comparison for $\mathrm{N}$ atom, but for $\mathrm{O}$ atom the charges mostly as the same in the three complexes. 
Table 2

NBO charges of the studied M-complexes using computational analysis.

\begin{tabular}{|llll|}
\hline Atom & Pd-complex & Zn-complex & Ni-complex \\
& DFT/LanL2DZ & DFT/LanL2DZ & DFT/LanL2DZ \\
\hline M1 & 0.187 & 1.043 & 0.242 \\
\hline S2 & 0.381 & 0.198 & 0.369 \\
\hline Cl3 & -0.396 & -0.626 & -0.397 \\
\hline Cl4 & -0.367 & -0.625 & -0.374 \\
\hline N5 & -0.532 & -0.664 & -0.553 \\
\hline C6 & -0.238 & -0.244 & -0.240 \\
\hline H7 & 0.261 & 0.241 & 0.261 \\
\hline H8 & 0.230 & 0.240 & 0.228 \\
\hline C9 & -0.079 & -0.079 & -0.078 \\
\hline H10 & 0.176 & 0.180 & 0.176 \\
\hline H11 & 0.234 & 0.232 & 0.234 \\
\hline C12 & -0.078 & -0.079 & -0.078 \\
\hline H13 & 0.234 & 0.233 & 0.234 \\
\hline H14 & 0.175 & 0.178 & 0.175 \\
\hline C15 & -0.244 & -0.251 & -0.246 \\
\hline H16 & 0.223 & 0.239 & 0.222 \\
\hline H17 & 0.261 & 0.242 & 0.262 \\
\hline C18 & -0.227 & -0.229 & -0.228 \\
\hline H19 & 0.239 & 0.236 & 0.237 \\
\hline H20 & 0.223 & 0.219 & 0.222 \\
\hline C21 & -0.508 & -0.510 & -0.511 \\
\hline H22 & 0.246 & 0.254 & 0.243 \\
\hline H23 & 0.250 & 0.250 & 0.251 \\
\hline C24 & -0.168 & -0.177 & -0.164 \\
\hline C25 & -0.233 & -0.226 & -0.233 \\
\hline & & & \\
\hline
\end{tabular}




\begin{tabular}{|llll|}
\hline Atom & Pd-complex & Zn-complex & Ni-complex \\
& DFT/LanL2DZ & DFT/LanL2DZ & DFT/LanL2DZ \\
\hline H26 & 0.225 & 0.230 & 0.227 \\
\hline C27 & -0.201 & -0.203 & -0.201 \\
\hline H28 & 0.227 & 0.226 & 0.227 \\
\hline C29 & -0.203 & -0.204 & -0.204 \\
\hline H30 & 0.227 & 0.226 & 0.227 \\
\hline C31 & -0.193 & -0.198 & -0.194 \\
\hline H32 & 0.232 & 0.231 & 0.231 \\
\hline C33 & -0.206 & -0.217 & -0.208 \\
\hline H34 & 0.254 & 0.251 & 0.252 \\
\hline 035 & -0.612 & -0.617 & -0.613 \\
\hline
\end{tabular}

Quantitative structure activity relationship (QSAR) mainly depends on the core indices construct the activity versus stability framework of complexes. The insight to energy leading to investigation the highest occupied and lowest unoccupied molecular orbital energies $\left(\mathrm{E}_{\mathrm{HOMO}}\right.$ and $\left.\mathrm{E}_{\mathrm{LUMO}}\right)$ which control the electronic properties of the studied complexes.

Some important reactivity parameters were calculated as the following:

$\mathrm{I}=-\mathrm{E}_{\mathrm{HOMO}}(1)$

$A=-E_{\text {LUMO }}(2)$

$\eta=(I-A) / 2(3)$

$\mu=-(1+A) / 2(4)$

$\sigma=1 / \eta(5)$

$E_{G A P}=E_{L U M O}-E_{\text {HOMO }}(6)$

The data calculated present in Table 3 where the dipole moment values indicate whether is most polarizable compound. Pd-complex show higher dipole moment value (13.335) then Ni-complex (12.838) and the the lower is of $\mathrm{Zn}$-complex (10.877). the relation between these parameters and stability of compounds can mainly help in the chemical reactions whose these compounds associated [25]

The frontier molecular orbitals (FMOs) of Pd-complex occur in levels with energies enough to motivate compound stabilization $\left(\mathrm{E}_{\mathrm{GAP}}=5.74 \mathrm{ev}\right)$ through electron transition where it is relatively small compared 
with the other complexes. Also, other parameters significantly control the compounds stability and reactivity such as ionization potential (I), electron affinity $(A)$, chemical potential $(\mu)$, chemical hardness $(\eta)$ and global softness $(\sigma)$ were calculated and tabulated. Also, a helpful polarizability index (a) was calculated and indicated that $\mathrm{Pd}$-complex is the most polarizable molecular structure (207.089).

Figure 4 shows the FMOs of the studied complexes with the energy of each level where the highest occupied molecular orbital ( $\mathrm{HOMO}$ ) contribution is mainly on the whole coordinated $\mathrm{N}$ ring bearing $\mathrm{O}$ atom in both $\mathrm{Pd}$ and $\mathrm{Ni}$ complexes, but this contribution not appear in $\mathrm{Zn}$-complex. This aimed to that $\mathrm{Pd}$ and Ni-morpholine derivative complexes mostly act in the same as structural and electronic behavior.

Table 3

Reactivity parameters of the studied complexes in gas phase with B3LYP/6-311g (d,p)

\begin{tabular}{|lllll|}
\hline Parameter & Pd-complex & Zn-complex & Ni-complex \\
\hline E (Hartee) & -764.206 & -703.110 & -806.778 \\
\hline D (debye) & 13.335 & 10.877 & 12.838 \\
$E_{\text {HOMO }}(e v)$ & -6.80 & -7.05 & -7.10 \\
$E_{\text {LUMO }}(e v)$ & -1.06 & -0.93 & -0.73 \\
$E_{\text {GAP }}(e v)$ & 5.74 & 6.12 & 6.37 \\
\hline & 6.80 & 7.05 & 7.10 \\
\hline$A$ & 1.06 & 0.93 & 0.73 \\
$\eta$ & 2.87 & 3.06 & 3.19 \\
$\mu$ & -3.93 & -3.99 & -3.92 \\
\hline$\sigma$ & 0.348 & 0.327 & 0.313 \\
\hline$a($ a.u. $)$ & 207.089 & 180.825 & 196.643 \\
\hline
\end{tabular}

\subsection{IR Spectroscopic analysis}

Differences in spectroscopic data analysis between the modulated and reported structures seem to be simple. Fig. 5 shows DFT/IR and Raman spectral bands obtained for the reported Pd complex and the modulated $\mathrm{Zn}$-, Ni-complexes. Vibrational frequencies were taken in the range of $500-4000 \mathrm{~cm}^{-1}$ and were performed by normal modes that corresponding to the ground state molecular electronic structure [26, 27].

The characteristic bands of the three studied molecular structures varies in their absorbance and scatter intensity from strong into weak contribution. Very simple variations in the peak position and intensity especially the position of M-coordinated atom peak due to the electronic environment surrounded by the 
band group. Mostly in all studied cases, the peaks appear in the position range $3238 \mathrm{~cm}^{-1}-3216 \mathrm{~cm}^{-1}$ are corresponding to $=\mathrm{C}-\mathrm{H}$ aromatic group, whereas the peaks located at $3181 \mathrm{~cm}^{-1}-3007 \mathrm{~cm}^{-1}$ are characteristic to $-\mathrm{C}-\mathrm{H}$ aliphatic group. $\mathrm{C}=\mathrm{C}$ stretching peak appear at $1626 \mathrm{~cm}^{-1}$. The observed peak at $1313 \mathrm{~cm}^{-1}$ is attributed to $\mathrm{C}-\mathrm{O}$ stretching bond analysis. There are also some weak peaks appear in the range $1081 \mathrm{~cm}^{-1}-1057 \mathrm{~cm}^{-1}$ that corresponding to $\mathrm{C}-\mathrm{C}$ and $\mathrm{C}-\mathrm{N}$ stretching single bonds. The band at 614 $\mathrm{cm}^{-1}$ is corresponding to $\mathrm{C}-\mathrm{S}$ bond. A strong peak appears at $1523 \mathrm{~cm}^{-1}$ is corresponding to $-\mathrm{C}-\mathrm{H}$ bending . Pd-N stretching band appears at $549 \mathrm{~cm}^{-1}$. Pd-Cl appears at $346 \mathrm{~cm}^{-1}$ but not occur in the computational scale. Ni-N band occurs at $552 \mathrm{~cm}^{-1}$, while Zn-N band appears at $536 \mathrm{~cm}^{-1}$.

\subsection{UV-Vis spectra detection (TD-DFT)}

CPCM model in DT-DFT method is best describe the behavior of electronic transitions in the molecular structure. Fig. 6 shows the different transition states for the studied optimized Pd, Zn and Ni complexes. It was observed that there are three transitions with different excitation environment. Mentioned to UV/Vis spectra of Pd-complex, the orbital contribution in the three transitions involve HOMO-2, HOMO-1 and HOMO to only LUMO state. This case indication about the limitation of electron transfer to higher unoccupied states and that must need higher absorption energy for successive electronic transitions. In case of Ni-complex, the peaks appear in higher wavelength range with small absorbance values, that may be increasing the difficulty for Ni-morpholine derivative crystal structure formation in the same condition of Pd-complex synthesis. The orbital contribution as the same in Pd-complex in transition to only LUMO level while there are successive transitions between $\mathrm{HOMO}$ and its lower states. In case of Zn-complex, UV/Vis spectra appeared at lower wavelength higher absorbance. These transitions are allowed for the ligand intra-excitation states $\left(n-\pi^{*}\right.$ and $\left.\pi-\pi^{\star}\right)$ but d-d transition, that distinguish the metal-ligand transition, not observed. The excitation energy for each transition and orbital contribution are tabulated in Table 4.

Table 4. Excitation energies, maximum wavelengths, oscillator strengths and \% orbital contribution for the studied experimental and modulated crystal structures. 


\begin{tabular}{|c|c|c|c|c|c|c|}
\hline Compound & $\begin{array}{l}\text { Spectral } \\
\text { line } \\
\text { number }\end{array}$ & $\begin{array}{l}\text { Excitation } \\
\text { energy } \\
(\mathrm{eV})\end{array}$ & $\underset{(\mathrm{nm})}{\lambda \max }$ & $F$ & $\begin{array}{l}\text { Type of } \\
\text { transition }\end{array}$ & $\begin{array}{l}\text { contribution \% } \\
\text { orbital }\end{array}$ \\
\hline \multirow{3}{*}{$\begin{array}{l}\text { Pd- } \\
\text { complex }\end{array}$} & 1 & 2.128 & 582.72 & 0.0023 & HOMO $\rightarrow$ LUMO & 64.8 \\
\hline & 2 & 2.295 & 540.31 & 0.0001 & $\begin{array}{l}\text { HOMO- } \\
1 \rightarrow \text { LUMO }\end{array}$ & 63.7 \\
\hline & 3 & 2.408 & 514.82 & 0.0041 & $\begin{array}{l}\text { HOMO- } \\
2 \rightarrow \text { LUMO }\end{array}$ & 56.2 \\
\hline \multirow{5}{*}{$\begin{array}{l}\mathrm{Ni}- \\
\text { complex }\end{array}$} & 1 & 1.071 & 1157.41 & 0.0001 & HOMO $\rightarrow$ LUMO & 60.37 \\
\hline & \multirow[t]{2}{*}{2} & \multirow[t]{2}{*}{1.372} & \multirow[t]{2}{*}{903.92} & \multirow[t]{2}{*}{0.0001} & $\begin{array}{l}\text { HOMO- } \\
2 \rightarrow \text { LUMO }\end{array}$ & 43.40 \\
\hline & & & & & $\begin{array}{l}\text { HOMO- } \\
1 \rightarrow \text { LUMO }\end{array}$ & 37.65 \\
\hline & \multirow[t]{2}{*}{3} & \multirow[t]{2}{*}{1.429} & \multirow[t]{2}{*}{867.74} & \multirow[t]{2}{*}{0.0001} & $\begin{array}{l}\text { HOMO- } \\
3 \rightarrow \text { LUMO }\end{array}$ & 52.10 \\
\hline & & & & & $\begin{array}{l}\text { HOMO- } \\
2 \rightarrow \text { LUMO }\end{array}$ & 20.04 \\
\hline \multirow[t]{6}{*}{$\begin{array}{l}\text { Zn- } \\
\text { complex }\end{array}$} & \multirow[t]{2}{*}{1} & \multirow[t]{2}{*}{5.227} & \multirow[t]{2}{*}{237.18} & \multirow[t]{2}{*}{0.0024} & $\begin{array}{l}\text { HOMO- } \\
2 \rightarrow \text { LUMO }\end{array}$ & 48.71 \\
\hline & & & & & $\begin{array}{l}\text { HOMO- } \\
1 \rightarrow \text { LUMO }\end{array}$ & 47.40 \\
\hline & \multirow[t]{2}{*}{2} & \multirow[t]{2}{*}{5.372} & \multirow[t]{2}{*}{230.81} & \multirow[t]{2}{*}{0.0610} & $\begin{array}{l}\text { HOMO- } \\
1 \rightarrow \text { LUMO }\end{array}$ & 53.20 \\
\hline & & & & & HOMO $\rightarrow$ LUMO & 35.60 \\
\hline & \multirow[t]{2}{*}{3} & \multirow[t]{2}{*}{5.469} & \multirow[t]{2}{*}{226.70} & \multirow[t]{2}{*}{0.0369} & $\begin{array}{l}\text { HOMO- } \\
1 \rightarrow \text { LUMO }\end{array}$ & 33.99 \\
\hline & & & & & HOMO $\rightarrow$ LUMO & 60.39 \\
\hline
\end{tabular}

\subsection{Hirschfeld surface analysis of Pd-complex structure}

This type of analysis discusses the percent quantity of crystal structure intermolecular contacts represented with red spots. Fig. 7 shows these surface analytical contacts for Pd-complex. 3D-fingerprint plots in Fig. 8 give evolution about the percent atom pairs contacts where all the contact atom pair types present as a whole percent $100 \%$. The close contact between the inside $\mathrm{Cl}$ layered atom to the outside $\mathrm{H}$ atom gives $18.4 \%$. The inside $\mathrm{O}$ to outside $\mathrm{H}$ gives $3.5 \%$, while the inside $\mathrm{S}$ atom to outside $\mathrm{H}$ atom gives $2.5 \%$ contact.

The crystal packing of $\mathrm{Pd}$-complex (unit cell dimensions 1:1:1) present in Fig. 9 as the close intermolecular contacts are represented in red lines. The maximum bond distance of these contacts was 
chosen as $2.70 \AA$ where there are different types of atom pair intermolecular contacts. Increasing the contact distance $(>2.70 \AA \hat{)})$, larger types of interactions appear around the crystal structure of Pdcomplex. Due to different types of heteroatoms, the crystal structure packing is strong between the molecules and that lead to a significant arrangement of the crystal structure [28].

\subsection{Molecular docking simulation}

As a part of molecular behavior for complexes toward the biological inhibition process, the studied metalmorpholine derivative complexes were docking investigated in binding with $106 \mathrm{~S}$ and 2BHM receptor codes.

Figure 10 visualizes the molecular docking of the three studied metal-complexes with either $106 \mathrm{~S}$ and $2 \mathrm{BHM}$ protein receptors. Furthermore, the best explored $106 \mathrm{~S}$ results of molecular docking for $\mathrm{Ni}$ - and $\mathrm{Zn}$ morpholine derivative complexes located in the same position pocket with total fitting energy of -59.80 $\mathrm{Kcal} / \mathrm{mol}$ and $-58.70 \mathrm{kcal} / \mathrm{mol}$ while the previously synthesized Pd-morpholine derivative complex in other protein position with total docking score of $-60.300 \mathrm{kcal} / \mathrm{mol}$. For the three complexes, the docking score energies are significantly the same but the difference in the type and number of bound protein amino acids. As shown from Table 5, Pd-complex binds with 7 amino acids and the mode of binding either $\mathrm{H}$ bond or VdW interaction through different heteroatoms of morpholine derivative ligand. While Ni-complex and $\mathrm{Zn}$-complex bind with 11 and 10 amino acids respectively with variation in binding site energy. In case of docking with 2BHM protein target, the best docked score found that Pd- and Zn- complexes bind with protein amino acids closely in similar position while Ni-complex bind in other position. This may depend on the electronic behavior on the surface of the complex where this is obvious from the ultrafolding of morpholine derivative ligand of $\mathrm{Zn}$-complex during docking analysis. Molecular docking data are present in Table 6, the total score energy for $\mathrm{Pd}$-,Ni- and $\mathrm{Zn}$-complexes are $-64.800,-65.400$ and $-61.200 \mathrm{kcal} / \mathrm{mol}$. Pd-complex is surrounded by 7 types of binding amino acids, but $\mathrm{Ni}$ - and $\mathrm{Zn}-$ complexes are surrounded by 6 binding amino acids in the target pocket. 
Table 5

the total energy score (fitting) of the studied M-complexes with 106S target

\begin{tabular}{|llll|}
\hline M- Complex & $\begin{array}{l}\text { Pd-morpholine } \\
\text { derivative }\end{array}$ & $\begin{array}{l}\text { Ni-morpholine } \\
\text { derivative }\end{array}$ & $\begin{array}{l}\text { Zn-morpholine } \\
\text { derivative }\end{array}$ \\
\hline $\begin{array}{l}\text { Energy } \\
\text { (kcal/mol) }\end{array}$ & -60.300 & -59.800 & -58.700 \\
\hline H- ASN-282 & -2.780 & 0.000 & 0.000 \\
\hline H- ASP-67 & 0.000 & -3.500 & -1.578 \\
\hline H- TYR-74 & 0.000 & -2.500 & 0.000 \\
\hline V- GLN-82 & 0.000 & -0.656 & -4.506 \\
\hline V- ARG-85 & 0.000 & -4.651 & -0.336 \\
\hline V- ASN-282 & -4.911 & 0.000 & 0.000 \\
\hline V- LYS-25 & -5.858 & 0.000 & 0.000 \\
\hline V- LYS-33 & -5.100 & 0.000 & 0.000 \\
\hline V- VAL-34 & -4.596 & 0.000 & 0.000 \\
\hline V- TYR-36 & -4.592 & 0.000 & 0.000 \\
\hline V-THR-57 & -4.945 & 0.000 & -0.000 \\
\hline V-S-GLU-64 & 0.000 & -4.157 & -9.861 \\
\hline V- PRO-65 & 0.000 & -2.206 & -4.286 \\
\hline V- LEU-66 & 0.000 & -5.541 & -5.389 \\
\hline V- ASP-67 & 0.000 & -1.877 & -5.712 \\
\hline V- ASP-67 & 0.000 & -3.689 & -6.278 \\
\hline V- ARG-70 & 0.000 & -8.589 & -038 \\
\hline V- ILE-71 & 0.000 & & -5.637 \\
\hline
\end{tabular}


Table 6

the total energy score (fitting) of the studied M-complexes with 2BHM target

\begin{tabular}{|llll|}
\hline complex & $\begin{array}{l}\text { Pd-morpholine } \\
\text { derivative }\end{array}$ & $\begin{array}{l}\text { Ni-morpholine } \\
\text { derivative }\end{array}$ & $\begin{array}{l}\text { Zn-morpholine } \\
\text { derivative }\end{array}$ \\
\hline $\begin{array}{l}\text { Energy } \\
\text { kcal/mol })\end{array}$ & -64.800 & -65.400 & -61.200 \\
\hline H- GLY-174 & 0.000 & -3.500 & 0.000 \\
\hline H- ASN-225 & -2.604 & 0.000 & -2.453 \\
\hline V- PRO-135 & -4.590 & 0.000 & -0.091 \\
\hline V- ASN-225 & -7.136 & 0.000 & 0.000 \\
\hline V- ASP-99 & 0.000 & -4.397 & 0.000 \\
\hline V-ASP-99 & 0.000 & -6.596 & 0.000 \\
\hline V-ASP-103 & 0.000 & -5.550 & 0.000 \\
\hline V- TYR-204 & 0.000 & -6.886 & 0.000 \\
\hline V- TYR-206 & 0.000 & -18.614 & 0.000 \\
\hline V- MET-131 & -0.997 & 0.000 & -5.511 \\
\hline V- MET-131 & -0.024 & 0.000 & -4.745 \\
\hline V- MET-212 & -0.237 & 0.000 & -6.061 \\
\hline V- ASN-225 & -6.858 & 0.000 & -2.754 \\
\hline
\end{tabular}

\section{Conclusion}

The metal-core exchangeable X-ray structure exported some important investigations related to different properties of the exchanged metal atoms, for example, the electronic and orbital configuration of the metal can alter the crystal structure and mode of binding. Pd-complex previously exhibit a distorted square planar structure in its crystal unit, but with exchangeable pattern, it was found that Zn-complex exhibited the distorted tetrahedral structure. In construct, Ni-complex appeared as a distorted square planar geometry in its modulated X-ray structure like Pd-complex. The electronic transition study investigated that there is some difficulty in synthesis of the modulated first periodic table raw complexes at the same conditions of Pd-synthesis. Molecular docking simulation analysis selected E-coli as the expression system to evaluate the total energy score of the three studied complexes with $106 \mathrm{~S}$ and 2BHM protein targets.

\section{Declarations}


The author declare that they have no known competing financial interests or personal relationships that could have appeared to influence the work reported in this paper.

\section{Funding}

No funding applicable for this article

\section{Conflicts of interest/Competing interests:}

No potential conflict of interest was reported by the authors

\section{Availability of data and material:}

My manuscript and associated personal data will be shared with Research Square for the delivery of the author dashboard.

\section{Code availability:}

Not available

\section{Author contributions:}

Material preparation, data collection, and analysis, the first draft of the manuscript was performed and written by Doaa S El-Sayed

\section{References}

1. Soliman AA, Amin MA, Sayed AM, Abou-Hussein AAA, Linert W, (2019) Cobalt and copper complexes with formamidine ligands: Synthesis, crystal X-ray study, DFT calculations and cytotoxicity. Polyhedron 161„, 213-221. https://doi.org/10.1016/j.poly.2018.12.020

2. Espino J, Fernández-Delgado E, Estirado S, Cruz-Martinez F, Villa-Carballar S, ViñuelasZahínos E, Luna-Giles F, Pariente JA (2020) Synthesis and structure of a new thiazoline-based palladium(II) complex that promotes cytotoxicity and apoptosis of human promyelocytic leukemia HL-60 cells. Sci Rep 1016745, https://doi.org/10.1038/s41598-020-73488-0

3. Oliveira CG, Romero-Canelón I, Coverdale JPC, Maia PIS, Clarkson GJ, Deflon NM, Sadler PJ (2020) Novel tetranuclear PdII and Ptll anticancer complexes derived from pyrene thiosemicarbazones. Dalton Trans 49:9595-9604. https://doi.org/10.1039/D0DT01133A

4. Navarro-Ranninger C, Zamora F, Masaguer JR, Pérez JM, González VM, Alonso C (1993) Palladium (II) compounds of putrescine and spermine. Synthesis, characterization, and DNA-binding and antitumor properties. J Inorg Biochem 52:137-149

5. Brudziñska I, Mikata Y, Obata M, Ohtsuki C, Yano S (2004) Synthesis, structural characterization, and antitumor activity of palladium(II) complexes containing a sugar unit. Bioorganic Medicinal Chemistry Letters 14:10 2533-2536 
6. Sharma NK, Ameta RK, Singh M (2016) Biological Impact of Pd (II) Complexes: Synthesis, Spectral Characterization, In Vitro Anticancer, CT-DNA Binding, and Antioxidant Activities", International Journal of Medicinal Chemistry, https://doi.org/10.1155/2016/9245619

7. Kizilcikli I, Kurt YD, Akkurt B et al (2007) Antimicrobial activity of a series of thiosemicarbazones and their $\mathrm{Zn}(\mathrm{II})$ and $\mathrm{Pd}(\mathrm{II})$ complexes. Folia Microbiol 52(1):15-25

8. Vieira LMM, de Almeida MV, Lourenço MCS, Bezerra FAFM, Fontes APS (2009) Synthesis and antitubercular activity of palladium and platinum complexes with fluoroquinolones. Eur $\mathrm{J}$ Med Chem 44(10):4107-4111

9. Biyala MK, Sharma K, Swami M, Fahmi N, Singh RV (2008) Spectral and biocidal studies of palladium(II) and platinum(II) complexes with monobasic bidentate Schiff bases. Transition Met Chem 33(3):377-381

10. Aghatabay NM, Somer M, Senel M, Dulger B, Gucin F, "Raman FT-IR (2007) NMR spectroscopic data and antimicrobial activity of bis[ $\mu_{2}$-(benzimidazol-2-yl)-2-ethanethiolato- $N, S, S$-chloro-palladium(II)] dimer, $\left[\left(\mu_{2}-\mathrm{CH}_{2} \mathrm{CH}_{2} \mathrm{NHNCC}_{6} \mathrm{H}_{4}\right) \mathrm{PdCl}\right]_{2} \cdot \mathrm{C}_{2} \mathrm{H}_{5} \mathrm{OH}$ complex. Eur J Med Chem 42(8):1069-1075

11. Fernández-Delgado E et al (2020) Pt(II) and Pd(II) complexes with a thiazoline derivative ligand: synthesis, structural characterization, antiproliferative activity and evaluation of pro-apoptotic ability in tumor cell lines HT-29 and U-937. J Inorg Biochem 202:110870

12. Małecki JG, Maroń A (2011) Spectroscopic, structure and DFT studies of palladium (II) complexes with pyridinetype ligands. Transition Met Chem 36:297-305. https://doi.org/10.1007/s11243-0119469-z

13. de Moura TR, Zanetti RD, Silva DES, de Farias RL, Mauro AE, Pereira JCM, de Souza AA, da Silva Siqueira F, de Souza WA, Júdice MA, Lima FV, Rocha VM, Deflon A (2020) Vieira de Godoy Netto, A. Palladium(ii) complexes bearing 1-iminothiolate-3,5-dimethylpyrazoles: synthesis, cytotoxicity, DNA binding and enzymatic inhibition studies. New J Chem 44:19891-19901. https://doi.org/10.1039/D0NJ02825H

14. Ferraz KSO, Ferandes L, Carrilho D, Pinto MCX, Leite MdF, Souza-Fagundes EM, Speziali NL, Mendes IC, Beraldo H (2009) 2-Benzoylpyridine-N(4)-tolyl thiosemicarbazones and their palladium(II) complexes: Cytotoxicity against leukemia cells. Biorg Med Chem 17:7138-7144. https://doi.org/10.1016/j.bmc.2009.08.063

15. Kira IP, Vladlena OB, llya AY, V.A. Maxim Alexandr VP, Square-Planar Heteroleptic Complexes of aDiimine-Nill-CatecholateType:Intramolecular Ligand-to-Ligand Charge Transfer Molecules 2021, 26, 4622. https://doi.org/10.3390/molecules26154622

16. Benedix R, Hennig $H$, Kunkely $H$, Vogler A (1990) Optical ligand-to-ligand charge transfer of $\mathrm{Zn}(2,20$ bipyridyl)(3,4-toluenedithiolate). Chem Phys Lett 175:175, 483-487

17. Cameron LA, Ziller JW, Heyduk AF, Near-IR absorbing donor-acceptor ligand-to-ligand chargetransfer complexes of nickel (II). Chem. Sci.7(2016) 1807-1814

18. Singh P, Das D, Prakash O, Singh AK (2013) Synthesis and structural chemistry of N-\{2(arylthio/seleno)ethyl\}morpholine/piperidine-palladium(II) complexes as potent catalysts for the 
Heck reactionInorganica. Chimica Acta 394:77-84

19. M. J. Frisch, et al; Gaussian 09, Revision A.02, Gaussian, Inc., Wallingford CT, (2016).

20. Becke AD (1993) A new mixing of Hartree-Fock and local density- functional theories. J Chem Phys 98:5648. https://doi.org/10.1063/1.464304

21. Dennington R, Keith TA, Millam JM, GaussView, Version 6.1, Semichem Inc., Shawnee Mission, KS, 2016

22. Macrae CF, Sovago I, Cottrell SJ, Galek PTA, McCabe P, Pidcock E, Platings M, Shields GP, Stevens JS, Towler M, Wood PA (2020) J Appl Cryst 53:226-235. [DOI: 10.1107/S1600576719014092]

23. Y.F. Chen, Y.J. Chen, J.M. Yang, GEMDOCK: An Integrated Environment for Computer-aided Drug Design and Its Applications, (2007)

24. Spackman PR, Turner MJ, Mckinnon JJ, Wolff SK, Grimwood DJ, Jayatilaka D, Spackman MA (2021) Crystal explorer 21.5. University of Western Australia

25. P. Geerlings, F. De Proft. "Chemical Reactivity as Described by Quantum Chemical Methods" Int. J.Mol. Sci. 3(4) (2002) 276-309. https://doi.org/10.3390/i3040276

26. Manookian B, Hernandez ED, Baer MD, Mundy CJ, Jentoft FC, Auerbach SM (2020) Experimental and DFT Calculated IR Spectra of Guests in Zeolites: AcyclicOlefins and Host-Guest Interactions. J Phys Chem C 124(19):10561-10572

27. Ji Y, Yang X, Ji Z, Zhu L, Ma N, Chen D, Cao Y (2020) DFT-calculated IR spectrum amide I, II, and III band contributions of $\mathrm{N}$ methylacetamide fine components. ACS omega 5(15):8572-8578

28. L.H. Al-Wahaibi, J. Joubert, O. Blacque, et al. Crystal structure, Hirshfeld surface analysis and DFT studies of 5-(adamantan-1-yl)-3-[(4-chlorobenzyl)sulfanyl]-4-methyl-4H-1,2,4-triazole, a potential 11 $\beta$ HSD1 inhibitor. Sci Rep 9, (2019) 19745. https://doi.org/10.1038/s41598-019-56331-z.

\section{Figures}

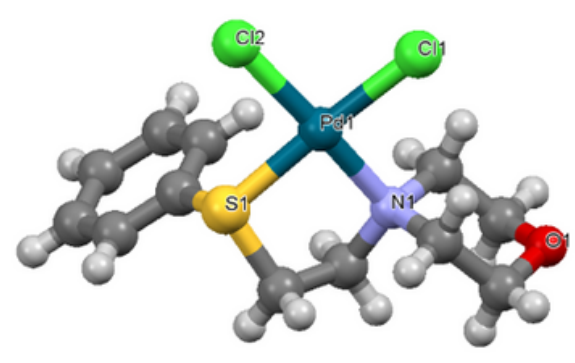

(a)

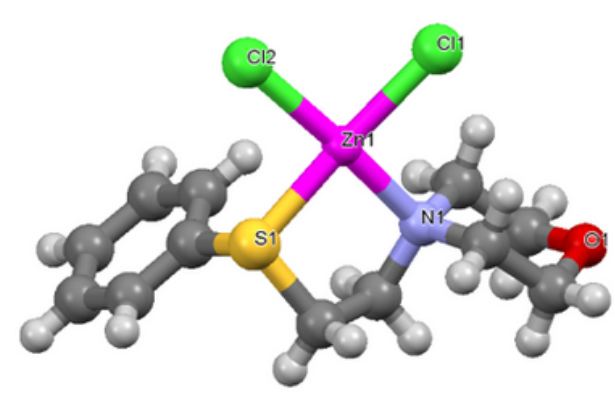

(b)

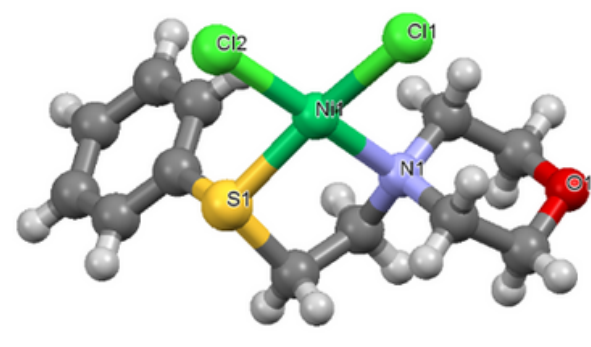

(c)

\section{Figure 1}

3D- Geometrical structure of (a) Pd- morpholine derivative (Synthesized crystal structure), (b) Znmorpholine derivative complex (modulated structure), and (c) Ni-morpholine derivative complex 
(modulated structure), with labeled coordinated centers
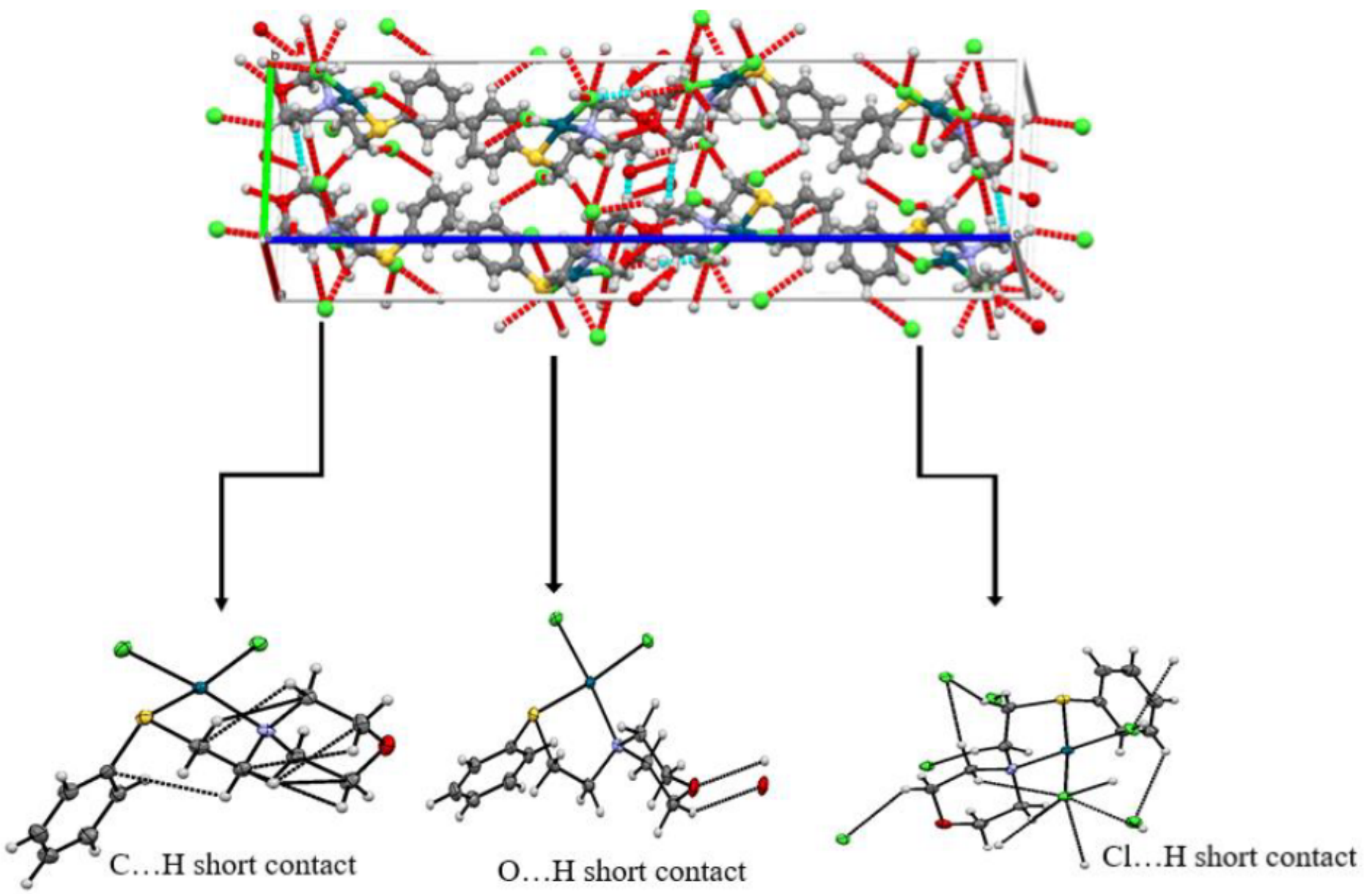

Figure 2

3D print packing X-ray structure of Pd-complex showing short intramolecular and intermolecular short contacts involving sum of VdW radii (dashed - red lines) with specific atoms contact contribution
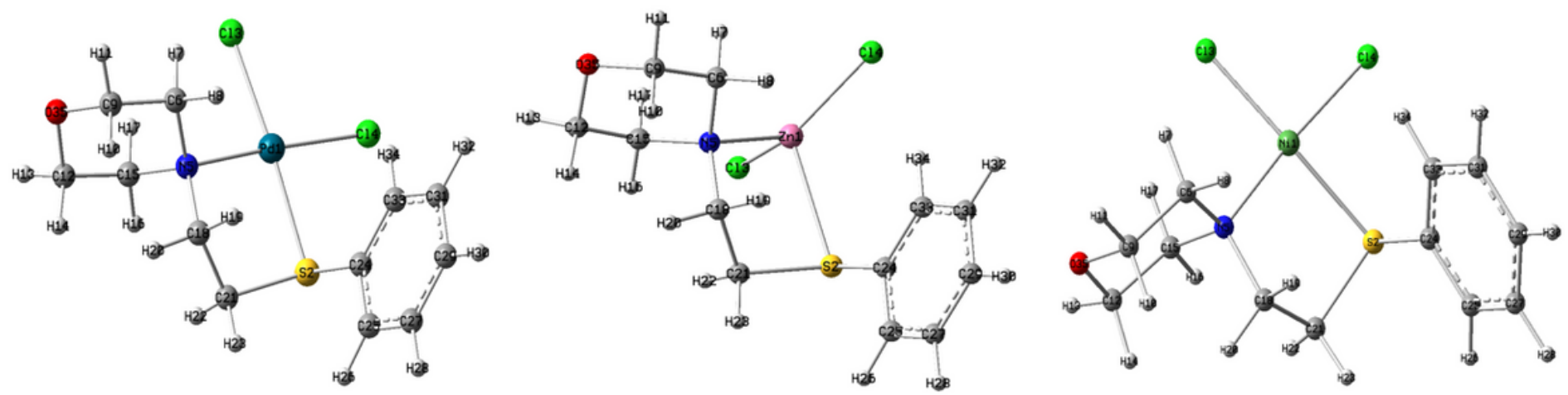

Figure 3

Optimized geometrical structures of metal complexes $(\mathrm{Pd}, \mathrm{Zn}, \mathrm{Ni}$ ) with full labeled atom numbers (using DFT/B3LYP method) 


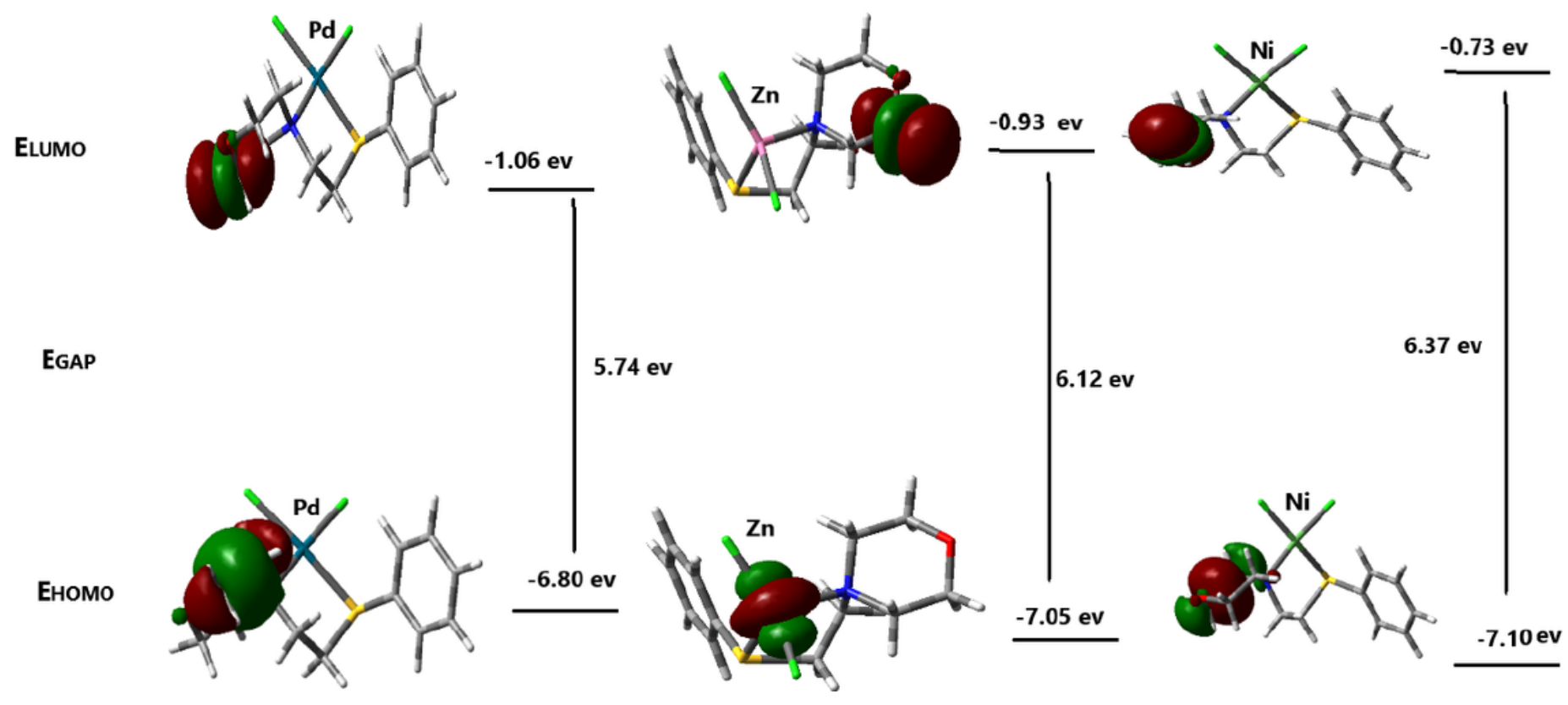

Figure 4

Schematic diagram describe FMOs energies of the studied complexes using DFT/B3LYP/LanL2DZ method 

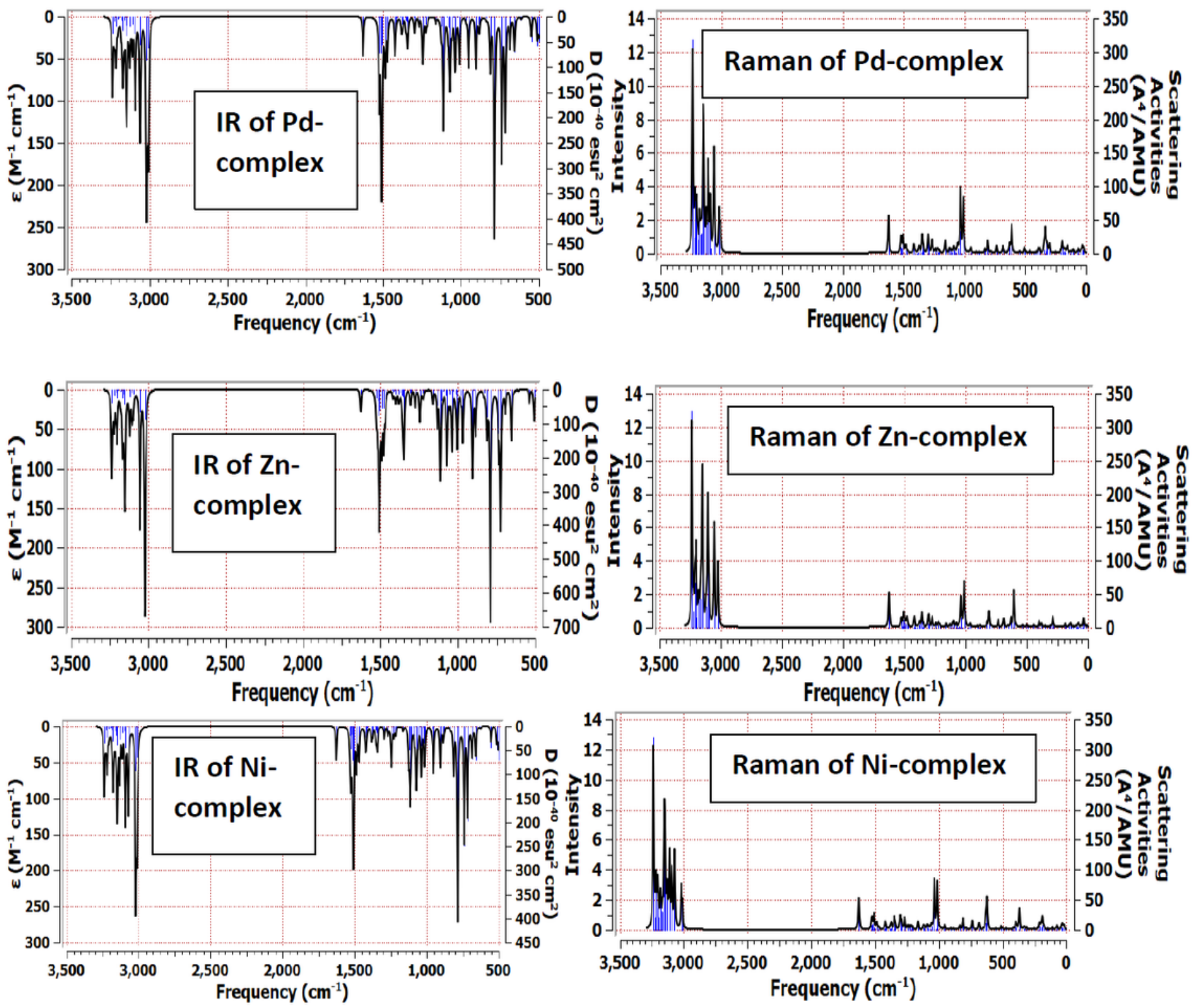

Figure 5

Calculated IR and Raman spectra of the optimized complexes 

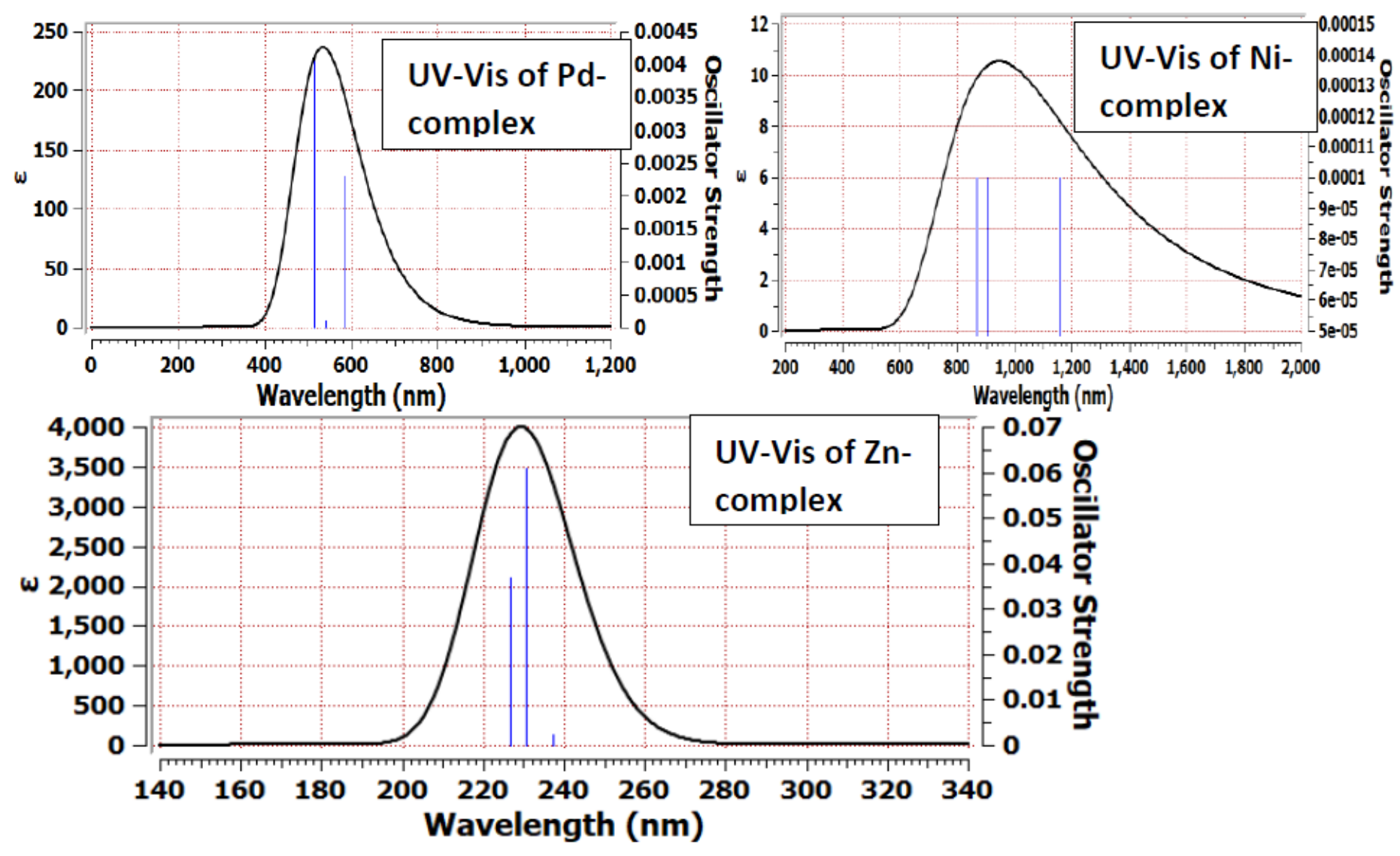

Figure 6

Investigated UV-Vis spectra of the studied complexes using TD-DFT method

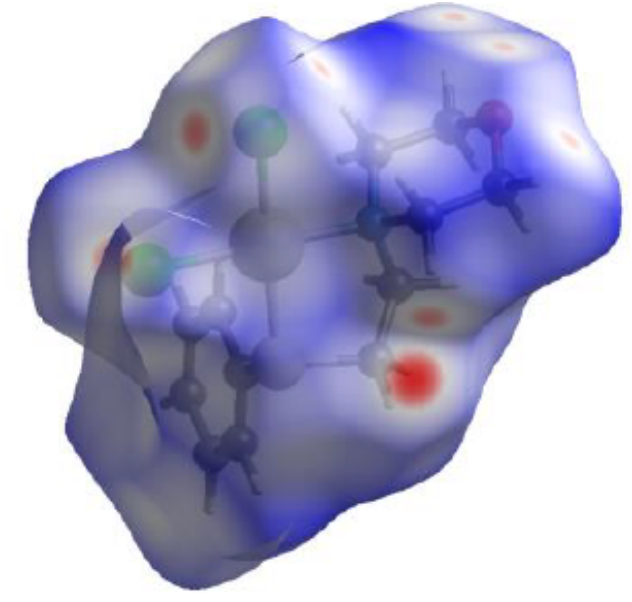

(a)

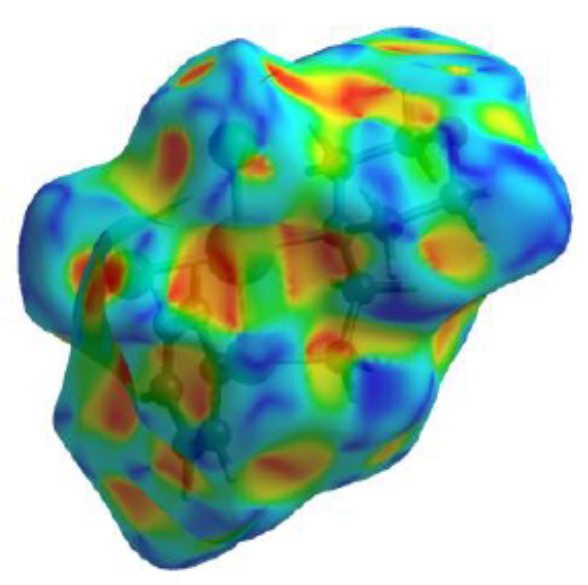

(b)

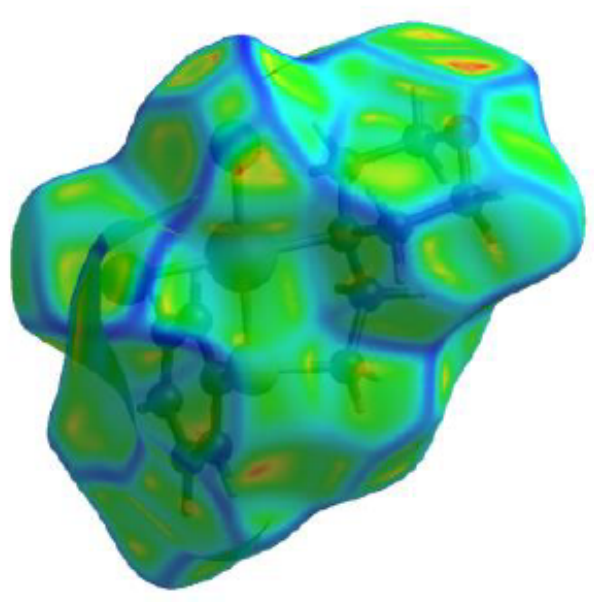

(c)

Figure 7

3D Hirshfeld surface analysis with red spot interactions for Pd-complex with (a) dnorm (-0.203 - 1.214)

(b) shape index (-1.00 -1.00) and (c) Curvedness (-4.00 -0.40) 

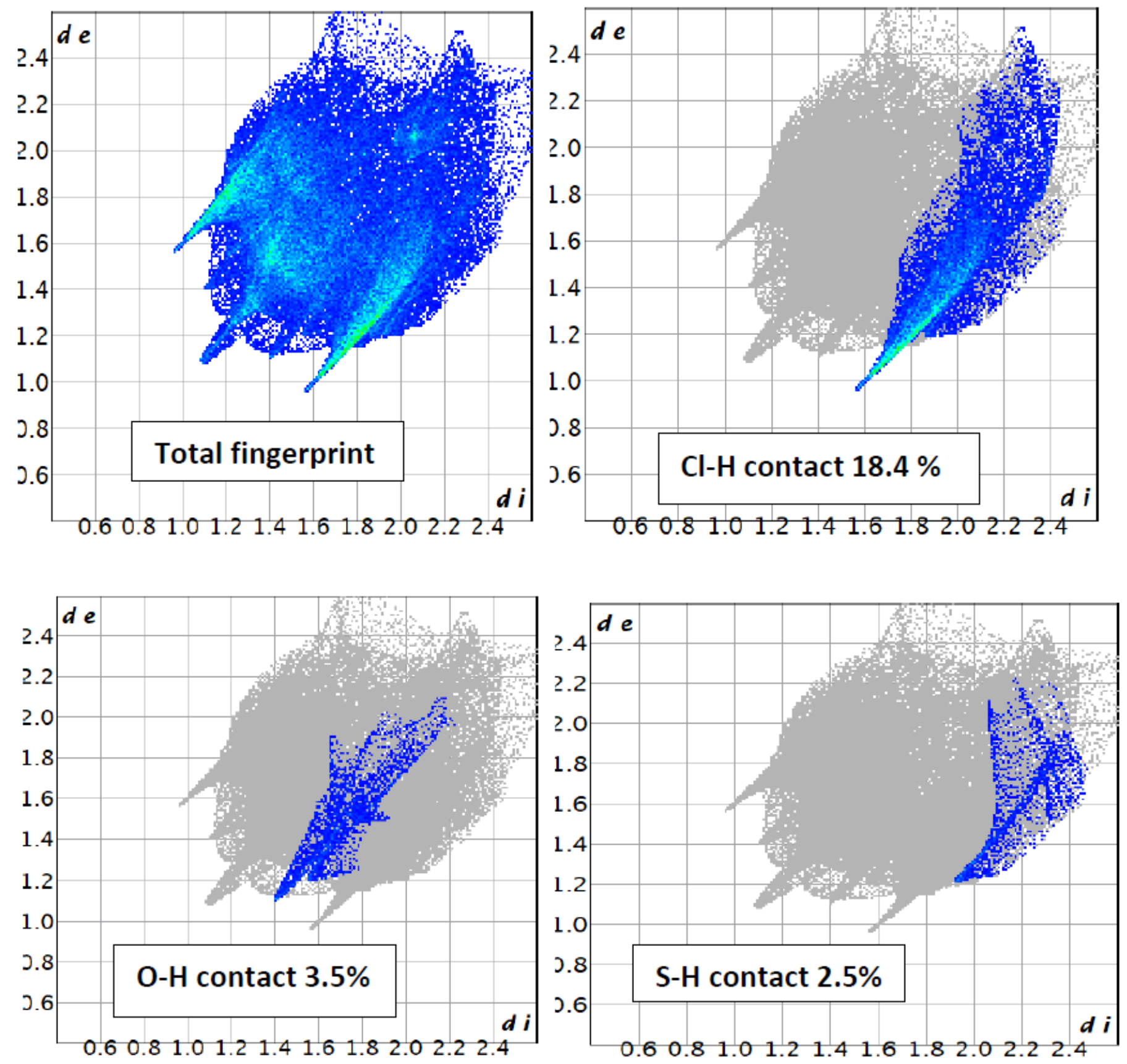

Figure 8

3D fingerprint for averall contacts and separate specific heteroatom-H contact 


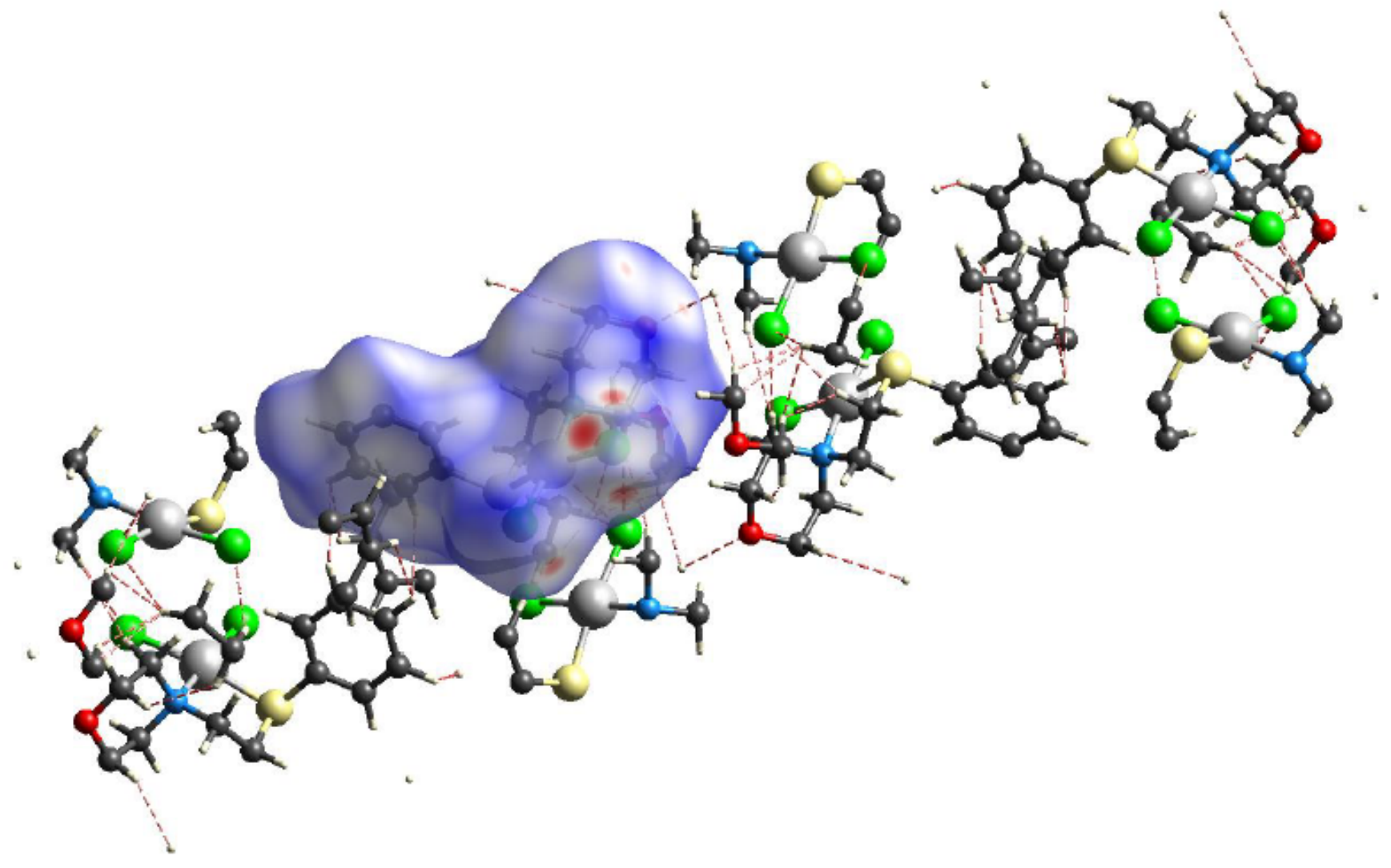

Figure 9

Hirschfeld analysis for one molecule present in a crystal structure (1:1:1) showing intramolecular and intermolecular contacts. 



Figure 10

Molecular docking of the studied M-morpholine derivative complexes with (a) 106S and (b) 2BHM, protein receptors

Supplementary Files 
This is a list of supplementary files associated with this preprint. Click to download.

- graphicalabstract.tif 